\title{
Salmonella detection in powdered dairy products using a novel molecular tool
}

\author{
Yueming Zhao, ${ }^{*}$ Xia Jiang, ${ }^{*}$ Yanyan Qu, ${ }^{*}$ Ruili Pan, ${ }^{*}$ Xinyi Pang, ${ }^{*}$ Yujun Jiang, ${ }^{*}{ }^{1}$ and Chaoxin Man ${ }^{* 1}$ \\ *Key Laboratory of Dairy Science, Ministry of Education, Department of Food Science, Northeast Agricultural University, Harbin, 150030, China \\ †National Research Center of Dairy Engineering and Technology, Northeast Agricultural University, Harbin, 150028, China
}

\begin{abstract}
In this study, we developed a rapid, specific, and sensitive loop-mediated isothermal amplification technique combined with a lateral flow dipstick (LAMP-LFD) method to detect Salmonella targeting the siiA gene in powdered infant formula (PIF). The specificity of the detection method (LAMP-LFD) approached $100 \%$ using 21 Salmonella and 31 non-Salmonella bacterial strains. This detection method exhibited high sensitivity limits for pure cultures at $3.7 \mathrm{cfu} / \mathrm{mL}$ and in PIF at 2.2 $\mathrm{cfu} / \mathrm{g}$ without enrichment. To evaluate the applicability of the LAMP-LFD method, we detected 60 positive PIF samples and 20 negative PIF samples. The results showed that the method of LAMP-LFD had a high diagnostic specificity of $100 \%$ for detection of Salmonella in PIF. To reduce incidence of LAMP contamination, we applied propidium monoazide (PMA) to eliminate carryover contamination of LAMP. At the same time, we found that PMA does not affect observation of LFD for measurement of LAMP signal. The results verified that the method of LAMP-LFD targeting the siiA gene is rapid, accurate, and sensitive for Salmonella detection in PIF, and that PMA shows great potential to be widely used to eliminate the amplicon contamination risk generated by the highly sensitive LAMP reaction in the detection process.
\end{abstract}

Key words: loop-mediated isothermal amplification, lateral flow dipstick, Salmonella, powdered infant formula

\section{INTRODUCTION}

Salmonella is one of the most common foodborne pathogenic bacteria worldwide, infecting humans and a variety of other animals via their respective habitats, feeding activities, or reservoirs (Zhao et al., 2003; Alves et al., 2015). Thus, Salmonella can infect humans by

\footnotetext{
Received December 30, 2016.

Accepted January 21, 2017.

${ }^{1}$ Corresponding authors: yujun_jiang@163.com and mcxwh2006@ qq.com
}

improper cooking and processing of foods of animal origin such as raw milk, meat, and eggs (Moussa et al., 2010). If ingested, Salmonella may cause diseases such as typhoid fever and salmonellosis (Salzman et al., 2003; Zhang et al., 2003). Previous studies have reported that powdered infant formula (PIF) is a newly identified source of Salmonella infection in infants, leaving the dairy industry with a high priority to develop innovative means to detect Salmonella in PIF (Cahill et al., 2008).

Conventional culture-based methods for detection of Salmonella require 2 to 3 d (Salam et al., 2013) and are not suitable for rapid detection of Salmonella. In recent years, many methods have been developed to rapidly detect nucleic acid targets of Salmonella, including PCR, real-time PCR, and loop-mediated isothermal amplification (LAMP; Zhao et al., 2010; Maciel et al., 2011). The methods of PCR and real-time PCR have many disadvantages, including a relatively high cost for equipment and consumables, and the need for trained personnel. However, LAMP is based on a nucleic acid amplification approach developed by Notomi et al. (2000). It may generate up to $10^{9}$ copies of the target DNA within $1 \mathrm{~h}$ using a specific stem-loop structure based on auto-cycling strand displacement and isothermal conditions $\left(60\right.$ to $65^{\circ} \mathrm{C}$; Notomi et al., 2000). Therefore, LAMP is a fast, isothermal process (requiring only a heat block) and is robust, offering greater sensitivity than other comparable methods (Mori and Notomi, 2009). Thus, it is a method with great promise for food safety applications, or clinical diagnostics, especially for resource-poor laboratories (Dhama et al., 2014; Kokkinos et al., 2014). Many different monitoring methods are available for results of LAMP, including agarose gel electrophoresis (AGE), real-time turbidity measurement (Wang et al., 2012), electrochemical methods (Safavieh et al., 2012), lateral flow dipstick (LFD; Jung et al., 2015), or ELISA-based quantification (Ravan and Yazdanparast, 2012). Previous studies have reported that the visual detection method of LFD have many advantages such as rapid speed, long-term stability, accuracy, user-friendly format, and not requiring expensive laboratory equipment (Peng et al., 2014). 
Thus, LFD is the preferred method and has attracted significant attention (Rigano et al., 2014).

Many target genes have been used to detect Salmonella by different methods. Some, such as iroB, hilA, $r f b$, opmC, and $i n v A$ are occasionally detected in some non-Salmonella bacteria (Luk et al., 1993; Bäumler et al., 1997; Ziemer and Steadham, 2003; De Clercq et al., 2007; Chen et al., 2011). Conversely, genes such as $\operatorname{im} A$, iroB, pipA, and stn may not be detected in all Salmonella strains (Bäumler et al., 1997; Khoo et al., 2009; Smith et al., 2010; Wang et al., 2013). It is worth mentioning here that invA encodes a Salmonella invasion protein and is thus considered a virulence gene located on Salmonella pathogenicity island (SPI) 1, so it is frequently used to detect Salmonella (Chen et al., 2011). However, several studies have shown that some Salmonella strains including the important strain of Salmonella Kentucky lack this gene (Turki et al., 2012). Therefore, a more specific and conserved gene is needed as an ideal target for accurate detection of Salmonella in food. The Salmonella SPI4 has an important role in intra-macrophage survival and cooperation with the SPI for invasion (Gerlach et al., 2008). The SPI4 region includes genes from siiA to siiF that are important for adhesion to polarized epithelial cells (Kiss et al., 2007). Wille et al. (2014) reported that siiA and siiB encode novel type I secretion system subunits that have important roles in controlling the SPI4-mediated adhesion of Salmonella enterica. Also, the siiA-regulatory protein is essential for SPI4-encoded type I secretion system function and can affect the expression of Salmonella virulence genes (Gerlach et al., 2007; Wille et al., 2014). Therefore, siiA has an extremely important role in the field of Salmonella pathogenesis. Hassena et al. (2015) used the novel gene of siiA to detect Salmonella by the conventional method of real-time PCR (Hassena et al., 2015). To the best of our knowledge, this is the first report using the LAMP and LAMP-LFD methods to specifically target the siiA gene for detection of Salmonella in a dairy food safety application.

It is well known that after repeated experiments, spurious aerosolized LAMP amplicons of various lengths may be present in pipettes, equipment, reaction reagents, the working environment, and even experimenters' skin (He and Xu, 2011; Kil et al., 2015). Amplicon amounts less than 10 ag have been successfully used to simulate the level of aerosol droplets, confirming contamination (Hsieh et al., 2014). Therefore, the high sensitivity of LAMP might also become its largest potential disadvantage (Ou et al., 2014). Also, it is of great significance to eliminate any contamination from previous LAMP reactions. Until now, some methods to eliminate carryover contamination have been established, such as the use of separate rooms for each step of LAMP, $5 \%$ sodium hypochlorite solution to wipe the surface of the entire experimental environment, UV light (Ou et al., 2014), uracil-DNA-glycosylase (Hsieh et al., 2014), a closed tube with an agar dye capsule (Karthik et al., 2014), and overlaying the top of the LAMP reaction mixture with sterile mineral oil $(\mathrm{Wu}$ et al., 2014). Although the results of these methods are credible and effective, it could be time-consuming, labor-intensive, occasionally inhibitory to LAMP amplification, and unable to eliminate the contaminants from the environment. It is well known that propidium monoazide (PMA) has been applied in selective detection of viable bacteria and removal of exogenous DNA signal in quantitative PCR experiments (Elizaquível et al., 2012; Schnetzinger et al., 2013). Therefore, PMA appears to be useful for the elimination of LAMP carryover contamination.

In this study, we used the siiA gene to develop a rapid, specific, and sensitive LAMP-LFD method for the detection of Salmonella in PIF and applied PMA to eliminate the LAMP carryover contamination. Thus, the aim of this study was to provide an accurate, fast, sensitive, and convenient detection system for the detection of Salmonella in the dairy industry.

\section{MATERIALS AND METHODS}

\section{Bacterial Strains and DNA Extraction}

A total of 50 bacterial strains including 21 Salmonella strains and 31 non-Salmonella strains were used to evaluate the specificity of the LAMP method (Tables 1 and 2). All Salmonella strains were grown in $20 \mathrm{~mL}$ of $\mathrm{NB}$ medium at $37^{\circ} \mathrm{C}$ shaking at $5 \times g$ for $8 \mathrm{~h}$ to achieve late-log phase $\left(10^{8} \mathrm{cfu} / \mathrm{mL}\right)$. Non-Salmonella strains were cultured in $20 \mathrm{~mL}$ of TSB medium under similar conditions.

In this study, Salmonella Typhimurium ATCC 14028 was used as the positive control and the template DNA was extracted from $1 \mathrm{~mL}$ of bacterial culture by the Gen Elute Bacterial Genomic DNA Kit (TIANGE, Beijing, China) following the manufacturer's instructions (http://www.tiangen.com/?productShow/t1/1/id/18. html) and suspended in $100 \mu \mathrm{L}$ of Tris-EDTA buffer. Templates were stored at $-20^{\circ} \mathrm{C}$ until further use.

\section{LAMP Target Sequence and Primer Design}

The LAMP primers were designed based on the conserved sequence between the Salmonella siiA gene (STM4257, GenBank accession number: NC_003197) and the 7 different strains of Salmonella Pathogenicity Island 4 genomic sequence (GenBank accession numbers: AJ576316, KP234069.1, KP234070, KP234071, 
KP234072, KP234073, and KP234074.1). A set of 4 primers including 2 outer primers (F3 and B3) and 2 inner primers (FIP and BIP) were designed by the PrimerExplorer V4 software (http://primerexplorer.jp/ elamp4.0.0/index.html). Then the specificity of the amplified fragment and all primers was assessed by searching the basic local alignment search tool (BLAST) in the National Center for Biotechnology and Information. The 2 inner primers (FIP and BIP) were labeled with fluorescein isothiocyanate (FITC) and biotin at the $5^{\prime}$ end, respectively. The primer sequences were shown in Table 3 and Figure 1. All the primers were synthesized commercially by Invitrogen (Shanghai, China).

\section{LAMP Assay}

Each LAMP reaction mixture included $0.2 \mu M$ F3 and B3, 1.6 $\mu M$ FIP and BIP primers, $2.5 \mu \mathrm{L}$ of 10 $\times$ ThermoPol Buffer (New England BioLabs, Ipswich, MA), $1.8 \mathrm{~m} M$ each deoxynucleoside triphosphate, 4 $\mathrm{m} M \mathrm{MgSO}_{4}, 0.9 \mu \mathrm{L}$ of $8 \mathrm{U} / \mu \mathrm{L}$ Bst 2.0 WarmStart DNA polymerase (New England BioLabs), $2 \mu \mathrm{L}$ of the target DNA $(68.5 \mathrm{ng} / \mu \mathrm{L})$, and nuclease-free water up to 25 $\mu \mathrm{L}$. A conventional water bath was used to incubate the LAMP assay reactions. Then, the reagent mixture was incubated at $65^{\circ} \mathrm{C}$ for $45 \mathrm{~min}$ in a water bath, followed by $80^{\circ} \mathrm{C}$ for $2 \mathrm{~min}$ to terminate each reaction.

\section{Lateral Flow Dipstick Setup and Assay}

Reagents and Instrumentation. Bovine serum albumin and sucrose were obtained from Sangon Biotech (Shanghai, China). The anti-FITC were acquired from Santa Cruz Biotechnology (Shanghai, China). The streptavidin was purchased from Sigma (St. Louis, MO) and anti-mouse secondary antibody was obtained from Bioss (Beijing, China). The nitrocellulose (NC) membranes were purchased from Sartorius (Göttingen, Germany). The conjugate pad, sample pad, absorption pad, and the plastic backing were acquired from Ahlstrom (Helsinki, Finland). The LFD cutter and sprayer were obtained by Autokun (Hangzhou, China) and Biodot (Irvine, CA), respectively.

Synthesis of Gold Nanoparticles Conjugated with Antibody. The gold nanoparticles (AuNP, 30 $\mathrm{nm}$ ) were obtained by the YiRui (Shenzhen, China). The conjugations were produced as follows: $3 \mu \mathrm{L}$ of the $0.2 \mathrm{MK}_{2} \mathrm{CO}_{3}$ was added into 1-mL AuNP solutions and sufficiently mixed to regulate the $\mathrm{pH}$ of AuNP, then $4.5 \mu \mathrm{L}$ of the anti-FITC $(1 \mathrm{mg} / \mathrm{mL})$ was added and incubated at room temperature for $15 \mathrm{~min}$, after which $100 \mu \mathrm{L}$ of $10 \%$ BSA was mixed and incubated at room temperature for $15 \mathrm{~min}$. Each solution was centrifuged at $12,000 \times g$ for $15 \mathrm{~min}$ at $4^{\circ} \mathrm{C}$. Subsequently, the dark red sediments (anti-FITC-AuNP conjugates) were

Table 1. Strains of Salmonella used for this study and the results for the loop-mediated isothermal amplification (LAMP) detection methods

\begin{tabular}{|c|c|c|c|c|}
\hline \multirow[b]{2}{*}{ No. } & \multirow[b]{2}{*}{ Bacterial species } & \multirow[b]{2}{*}{ Source $^{1}$} & \multicolumn{2}{|c|}{ Result $^{2}$} \\
\hline & & & LAMP-AGE & LAMP-LFD \\
\hline 1 & Salmonella Typhimurium & ATCC 14028 & $+^{3}$ & + \\
\hline 2 & Salmonella Typhimurium & ATCC 23564 & + & + \\
\hline 3 & Salmonella Typhimurium & Laboratory & + & + \\
\hline 4 & Salmonella Typhimurium & Laboratory & + & + \\
\hline 5 & Salmonella Dublin & CMCC 50042 & + & + \\
\hline 6 & Salmonella Arizona & CMCC(B) 47001 & + & + \\
\hline 7 & Salmonella enterica ssp. salamae & ATCC 43972 & + & + \\
\hline 8 & Salmonella Choleraesuis & CMCC 50018 & + & + \\
\hline 9 & Salmonella Pullorum & ATCC 9120 & + & + \\
\hline 10 & Salmonella Pullorum & Laboratory & + & + \\
\hline 11 & Salmonella Pullorum & Laboratory & + & + \\
\hline 12 & Salmonella Pullorum & Laboratory & + & + \\
\hline 13 & Salmonella Pullorum & Laboratory & + & + \\
\hline 14 & Salmonella Enteritidis & ATCC 13076 & + & + \\
\hline 15 & Salmonella Enteritidis & Laboratory & + & + \\
\hline 16 & Salmonella Enteritidis & Laboratory & + & + \\
\hline 17 & Salmonella Enterica paratyphi B & CMCC(B) 50094 & + & + \\
\hline 18 & Salmonella Typhi & CMCC(B) 50071 & + & + \\
\hline 19 & Salmonella Typhi & ATCC 19430 & + & + \\
\hline 20 & Salmonella Paratyphi A & $\mathrm{CMCC}(\mathrm{B}) 50093$ & + & + \\
\hline 21 & Salmonella Thompson & CMCC 50023 & + & + \\
\hline
\end{tabular}

${ }^{1}$ ATCC $=$ American Type Culture Collection; $\mathrm{CMCC}=$ National Center for Medical Culture Collections.

${ }^{2}$ LAMP-AGE $=$ the detection method of loop-mediated isothermal amplification-agarose gel electrophoresis. LAMP-LFD $=$ the detection method of loop-mediated isothermal amplification-lateral flow dipstick.

${ }^{3}+=$ positive result. 
Table 2. Strains of non-Salmonella used for this study and the results of the loop-mediated isothermal amplification (LAMP) detection methods

\begin{tabular}{|c|c|c|c|c|}
\hline \multirow[b]{2}{*}{ No. } & \multirow[b]{2}{*}{ Bacterial species } & \multirow[b]{2}{*}{ Source $^{1}$} & \multicolumn{2}{|c|}{ Result $^{2}$} \\
\hline & & & LAMP-AGE & LAMP-LFD \\
\hline$\overline{1}$ & Staphylococcus aureus & CMCC 26074 & $-{ }^{3}$ & - \\
\hline 2 & Staph. aureus & CMCC 26075 & - & - \\
\hline 3 & Staph. aureus & ATCC 25923 & - & - \\
\hline 4 & Staph. aureus & ATCC 29213 & - & - \\
\hline 5 & Staph. aureus & ATCC 12600 & - & - \\
\hline 6 & Staph. aureus & ATCC 13565 & - & - \\
\hline 7 & Staph. aureus & ATCC 12598 & - & - \\
\hline 8 & Bacillus cereus & CMCC 63303 & - & - \\
\hline 9 & B. cereus & ATCC 14579 & - & - \\
\hline 10 & Cronobacter sakazakii & ATCC 29544 & - & - \\
\hline 11 & C. sakazakii & ATCC 51329 & - & - \\
\hline 12 & Escherichia coli & ATCC 25922 & - & - \\
\hline 13 & Shigella flexneri & CMCC 51572 & - & - \\
\hline 14 & Listeria innocua & ATCC 33090 & - & - \\
\hline 15 & Staphylococcus epidermidis & ATCC 12228 & - & - \\
\hline 16 & Listeria monocytogenes & CMCC 54004 & - & - \\
\hline 17 & L. monocytogenes & CMCC 54005 & - & - \\
\hline 18 & L. monocytogenes & CMCC 54006 & - & - \\
\hline 19 & Micrococcus luteus & Laboratory & - & - \\
\hline 20 & Enterococcus faecalis & Laboratory & - & - \\
\hline 21 & Shigella flexneri & CICC 21678 & - & - \\
\hline 22 & Bacillus subtilis & Laboratory & - & - \\
\hline 23 & E. coli $\mathrm{O} 157: \mathrm{H} 7$ & CICC 21530 & - & - \\
\hline 24 & L. monocytogenes & ATCC 19114 & - & - \\
\hline 25 & L. monocytogenes & ATCC 19116 & - & - \\
\hline 26 & L. monocytogenes & ATCC 19112 & - & - \\
\hline 27 & Listeria welshimeri & ATCC 43550 & - & - \\
\hline 28 & L. welshimeri & ATCC 43548 & - & - \\
\hline 29 & Vibrio parahaemolyticus & ATCC 33847 & - & - \\
\hline 30 & V. parahaemolyticus & ATCC 17802 & - & - \\
\hline 31 & Staphylococcus xylosus & ATCC 29971 & - & - \\
\hline
\end{tabular}

${ }^{1}$ ATCC $=$ American Type Culture Collection; $\mathrm{CMCC}=$ National Center for Medical Culture Collections

${ }^{2} \mathrm{AGE}=$ agarose gel electrophoresis; LFD = lateral flow dipstick.

${ }^{3}-=$ negative result.

suspended in $100 \mu \mathrm{L}$ of buffer [containing $100 \mathrm{~m} M$ Tris $\mathrm{pH} 8.0,0.2 \%$ BSA (wt/vol), and $4 \%$ trehalose (wt/vol)] and stored at $4^{\circ} \mathrm{C}$ before being used.

Assembly of the LFD. The schematic diagram of the LFD is illustrated in Figure 2. The LFD consists of 4 components: sample pad, conjugate pad, detection region with control line and test line, and absorbent pad. The sample and conjugate pad were made from glass fiber and saturated with the running buffer containing $100 \mathrm{~m} M$ Tris (pH 8.0), 0.2\% BSA (wt/vol), $0.05 \%$ casein (wt/vol), $4 \%$ trehalose (wt/vol), $0.5 \%$ Tween 20, and $0.05 \%$ sodium azide (wt/vol). Then the sample and conjugate pad were dried at $45^{\circ} \mathrm{C}$ for $2 \mathrm{~h}$. After that the conjugate pad was sprayed with the anti-FITC-AuNP conjugate and dried at $37^{\circ} \mathrm{C}$ for $2 \mathrm{~h}$. Streptavidin (5 $\mathrm{mg} / \mathrm{mL}$, dissolved in $100 \mathrm{~m} M$ Tris, $\mathrm{pH}$ 7.5) and antimouse secondary antibody $(1 \mathrm{mg} / \mathrm{mL})$ were sprayed with $1.0 \mu \mathrm{L} / \mathrm{cm}$ onto the NC membrane to form the test line and the control line on the detection region, respectively. Each distance between 2 adjacent detec-

Table 3. The sequences of loop-mediated isothermal amplification (LAMP) primers for the siiA gene of Salmonella

\begin{tabular}{lll}
\hline Primer $^{1}$ & Sequence $\left(5^{\prime}-3^{\prime}\right)$ & Item \\
\hline siiA-F3 & AGAAGCTTTTCAGAAGAGGA & \\
siiA-B3 & GATAATAGCTTTACTCGTTGTACT & $5^{\prime}$ modified biotin \\
siiA-FIP & CTGCCTGAGGAATAACCATTTCTATAATAAAGGCTTGGTTAGAAGACA & $5^{\prime}$ modified FITC ${ }^{2}$ \\
siiA-BIP & TACGACTGGGATATGAACGGGACTCATGTCAATAACTACATCAG & . \\
\hline
\end{tabular}

${ }^{1} \mathrm{~A}$ set of 4 primers including 2 outer primers (F3 and B3) and 2 inner primers (FIP and BIP).

${ }^{2} \mathrm{FITC}=$ fluorescein isothiocyanate. 
1 AGAAGCTTTTCAGAAGAGGA F3

61 AGTAATTTATTGATAGAAAT GGTTATTCCTCAGGCAGACA TCTCTTTCTCTGACTCTCTA 120

F1c

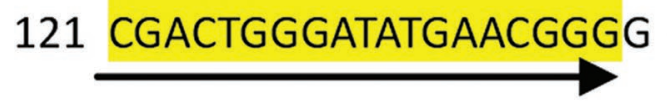

AATTATTTTGATGAAAGAGA

B1C

181 GTAGTTATTGACATGAGTGT

B2

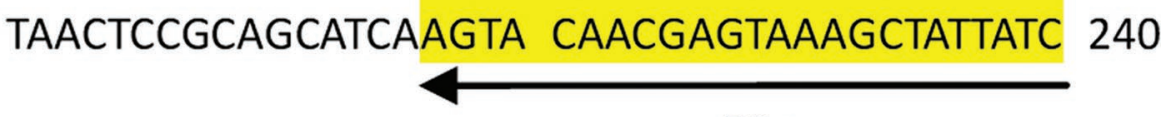

B3C

Figure 1. The target sequences for loop-mediated isothermal amplification (LAMP). The boxes and arrows show the sequences and direction of the LAMP primers. Color version available online.

tion lines was $1 \mathrm{~cm}$ and the $\mathrm{NC}$ membrane was then air-dried at room temperature. To assemble the test strip, the NC membrane was pasted on the center of the plastic backing and covered $2 \mathrm{~mm}$ with the absorbent pad and the conjugate pad on each side. The absorbent pad was on one end of the test strip. The other side of conjugate pad was covered $2 \mathrm{~mm}$ with the sample pad to the other end of the test strip. Then the LFD were cut to a width of $3 \mathrm{~mm}$ and stored at $4^{\circ} \mathrm{C}$ in a desiccated container.

The LAMP-LFD detection method was prepared by mixing $10 \mu \mathrm{L}$ of LAMP amplicons and $90 \mu \mathrm{L}$ of running buffer, then immersing the LFD into the mixture. The result was visualized within $15 \mathrm{~min}$. If the detection region presents 2 red lines (test line and control line), the result was confirmed to be positive. Only the control line appears as red in a negative result.

\section{PCR Assay}

The F3 and B3 of the LAMP outer primers (Table 3 ) were used as the PCR primers to detect Salmonella with an amplicon length of $240 \mathrm{bp}$. The composition of the PCR reaction mixture included $12.5 \mu \mathrm{L}$ of $2 \times$ Taq DNA polymerase buffer (TIANGE), $0.4 \mu M$ of the outer primers F3 and B3, $2 \mu \mathrm{L}$ of the prepared template DNA $(68.5 \mathrm{ng} / \mu \mathrm{L})$, and nuclease-free water up to a final volume of $25 \mu \mathrm{L}$. The PCR reactions were performed in the Veriti 96-Well Thermal Cycler (Applied Biosystems, Waltham, MA) with the following steps: an initial denaturation at $94^{\circ} \mathrm{C}$ for 3 min, each of the 30 cycles containing a denaturation at $94^{\circ} \mathrm{C}$ for $30 \mathrm{~s}$, an annealing at $58^{\circ} \mathrm{C}$ for $45 \mathrm{~s}$, and an elongation at $72^{\circ} \mathrm{C}$ for $1 \mathrm{~min}$, with a final elongation at $72^{\circ} \mathrm{C}$ for $5 \mathrm{~min}$. The results were observed by the $1 \% \mathrm{AGE}$.

\section{Specificity of LAMP-LFD}

Primer specificity was tested by amplifying 52 bacterial strains under optimum reaction conditions and observed by the LAMP-AGE and LAMP-LFD detection methods. All experiments were repeated 3 times.

\section{Assay Sensitivity for Pure Bacterial Culture and Powdered Infant Formula}

The Salmonella Typhimurium ATCC 14028 was aerobically cultured $8 \mathrm{~h}$ at $37^{\circ} \mathrm{C}(5 \times g)$ to achieve late-log phase. Then, sterilized $0.85 \%$ normal saline was used to 10-fold serially dilute the Salmonella Typhimurium ATCC 14028 to achieve concentrations ranging from $3.7 \times 10^{8}$ to $3.7 \times 10^{-2} \mathrm{cfu} / \mathrm{mL}$ and the density was evaluated by the standard plate counting method. Afterward, the different concentrations of genomic DNA were extracted by the method earlier described. Aliquots of the $2-\mu \mathrm{L}$ template DNA were used to detect the sensitivity of LAMP-LFD and PCR methods.

The PIF samples were purchased from a local retailer in Harbin, China, and the method of ISO 6579:2002 was used to determine that the samples were not con- 
taminated with Salmonella. After that $1 \mathrm{~mL}$ aliquots of the serial 10-fold dilutions of the target bacterial Salmonella Typhimurium ATCC 14028 was mixed with $8 \mathrm{~mL}$ of buffer peptone water (BPW), and then 1-g aliquots of PIF were added into the mixture to form the serial concentrations ranging from $2.2 \times 10^{8}$ to 2.2 $\times 10^{-2} \mathrm{cfu} / \mathrm{g}$. Then, the template DNA of $1 \mathrm{~mL}$ of the different concentrations of reconstituted PIF were extracted via the method previously described. Aliquots of the $2-\mu \mathrm{L}$ template DNA were used to detect the sensitivity of the LAMP-LFD and PCR methods in PIF without enrichment.

\section{PMA Treatment for Carryover Contamination of LAMP}

The stock solution of PMA (20 $\mathrm{m} M$ in nucleasefree water; Biotium Inc., Hayward, CA) was diluted in nuclease-free water to achieve different concentrations. The principle of PMA to eliminate the carryover contamination of LAMP is shown in Figure 3. Various concentrations of PMA $(18 \mu \mathrm{L})$ were mixed with $2 \mu \mathrm{L}$ of different concentrations of LAMP products $(1,000$ $\mathrm{ng} / \mu \mathrm{L}, 100 \mathrm{ng} / \mu \mathrm{L}, 10 \mathrm{ng} / \mu \mathrm{L}, 10 \mathrm{pg} / \mu \mathrm{L}, 10 \mathrm{fg} / \mu \mathrm{L}$, and $10 \mathrm{ag} / \mu \mathrm{L})$, respectively. In other words, the mass of



"'anti-FITC antibody "'anti-biotin antibody "'anti-mouse secondary

\section{products Anti-FITC-AuNP FIP labeled FITC BIP labeled biotin}

Figure 2. The schematic illustration of the lateral flow dipstick. FITC = fluorescein isothiocyanate; AuNP = gold nanoparticles; FIP and $\mathrm{BIP}=2$ inner primers. Color version available online. 




Figure 3. The principle of propidium monoazide (PMA) to eliminate the carryover contamination of loop-mediated isothermal amplification (LAMP). The treatment process includes 2 stages. In stage 1, PMA touches the LAMP amplicons in a contaminated environment at ambient temperature and then is exposed to halogen light of $1 \times 10^{5} \mathrm{~lx}$ to activate PMA. The photoreactive azide group in PMA is converted to an active nitrene group. In stage 2, the LAMP amplicons in the contaminated environment are covalently linked with the activated PMA permanently and will not be amplified, whereas the residual active PMA will become the hydroxylamine by reacting with water, with no capability to covalently bind to LAMP amplicons. Color version available online.

$2 \mu \mathrm{L}$ of different concentrations of LAMP products is equivalent to the mass ranging from 2,000 ng (a level $10^{11}$ times higher than the carryover contamination of aerosol droplets) to 20 ag (attograms; the level of the carryover contamination of aerosol droplets). The mixtures (the various concentrations of PMA mixed with the different concentrations of LAMP products) were mixed in a $0.2-\mathrm{mL}$ transparent microcentrifuge tube, and the tubes were placed horizontally at ambient temperature and exposed to a $650-\mathrm{W}$ halogen light source at a distance of $20 \mathrm{~cm}$ (illuminance $=111,500$ $\mathrm{lx}$ ) for $2 \mathrm{~min}$. The illuminance was measured by an LX101 Digital Light Lux Meter (ESUN, Kaohsiung City, Taiwan). To evaluate the results, $2-\mu \mathrm{L}$ aliquots of the treated mixtures were subjected to LAMP amplification. The results were analyzed by electrophoresis on a $2 \%$ agarose gel.

\section{Photolysis of PMA}

It is crucial to test that excessive levels of PMA can undergo complete photolysis under the light exposure conditions used here, and such inactivation of PMA does not affect amplification reactions. The LAMP amplicons were added to $20 \mu \mathrm{L}$ of the different con- centrations $(450,126,90,63$, and $45 \mu M)$ of PMA solutions to reach the final concentrations of $10 \mathrm{ag} /$ $\mu \mathrm{L}$, followed by exposing the different concentrations of PMA to a illuminance of $111,500 \mathrm{~lx}$ at $10 \mathrm{~min}$, at intervals to $120 \mathrm{~min}$. Mixtures were treated as mentioned above on ice to induce PMA crosslinking with the LAMP amplicons. Then aliquots of the $2 \mu \mathrm{L}$ mixtures were used as templates for LAMP reactions and the results were observed by electrophoresis on a $2 \%$ agarose gel.

\section{PMA Applied in LAMP-LFD Detection}

We used $18 \mu \mathrm{L}$ of nuclease-free water and $140 \mu \mathrm{M}$ PMA mixed with $2 \mu \mathrm{L}$ of LAMP products (at $5 \mathrm{ag} / \mu \mathrm{L}$, the minimum mass of products can occur the LAMP amplification) and then exposed to light $(111,500 \mathrm{~lx})$ for $100 \mathrm{~min}$, to demonstrate that the LAMP carryover contaminants treated by PMA can be reasonably applied in a practical test and the high concentration of PMA will not cause interference to the practical test results. Afterward, each of the $2-\mu \mathrm{L}$ mixtures was used as a template for re-amplification. Subsequently, a PMA-treated $(18 \mu \mathrm{L}$ of $140 \mu M$ PMA mixed with $2 \mu \mathrm{L}$ of $5 \mathrm{ag} / \mu \mathrm{L}$ of LAMP products exposed to $111,500 \mathrm{~lx}$ 
for $100 \mathrm{~min}$ ) mixture mixed with $1 \mathrm{ng} / \mu \mathrm{L}$ of the target DNA was used as a template for re-amplification. The results were observed by the detection methods of LAMP-AGE and LAMP-LFD.

\section{RESULTS}

\section{Optimization of the LAMP Assay}

To optimize the LAMP assay, we performed for the concentration of each reagents, reaction temperature, and reaction time. The optimal LAMP reaction conditions were detected by electrophoresis on $2 \%$ agarose gel and evaluated by the clearest characteristic ladderlike pattern. The results showed that the optimal ratio of outer primer to inner primer was 1:8 and the optimal conditions are $1.8 \mathrm{~m} M$ deoxynucleoside triphosphate, $4 \mathrm{mM} \mathrm{MgSO}_{4}$, and $0.9 \mu \mathrm{L}$ of Bst 2.0 WarmStart DNA polymerase (data not shown). The reaction was incubated at various temperature from 60 to $65^{\circ} \mathrm{C}$ for $1 \mathrm{~h}$, respectively. When the reaction was incubated at $65^{\circ} \mathrm{C}$, the LAMP products appeared to have the strongest signals (data not shown). Thus, the $65^{\circ} \mathrm{C}$ was selected as the optimal incubation temperature. Then the reaction was incubated for $15,30,45,60$, and $75 \mathrm{~min}$, respectively. When the reaction was incubated for $45 \mathrm{~min}$, the LAMP amplicons showed the clearest characteristic ladder-like pattern. Thus, we selected $45 \mathrm{~min}$ as the optimal reaction time (data not shown).

\section{Optimization of the LFD Methods}

To improve the sensitivity of the LAMP-LFD, we systematically optimized the LFD components by varying each parameter individually. In this study, we did a sensitivity test for each factor, and each parameter with the lowest sensitivity was chosen as the final LFD detection setting. The different concentrations of Tris $(50,100,150$, and $200 \mathrm{mM})$ were used to prepare the running buffer to determine the detection limits of LAMP-LFD, respectively. It was found that the Tris concentration of $100 \mathrm{~m} M$ obtained the lowest detection limits; thus, $100 \mathrm{mM}$ Tris is the optimal concentration in running buffer (data not shown). Then the $\mathrm{pH}$ value of Tris was prepared ranging from 6.5 to 9.0 in running buffer to determine the detection limits, respectively. The result was shown that the $\mathrm{pH} 8.0$ of Tris is the optimal condition for the running buffer. Following optimization, another factors of the running buffer are the $0.2 \%$ BSA (wt/vol), $0.05 \%$ casein (wt/vol), $4 \%$ trehalose (wt/vol), $0.5 \%$ Tween 20 , and $0.05 \%$ sodium azide (wt/vol), which provided a stable environment for LFD (Figure 4).

\section{Specificity and Sensitivity of LAMP-LFD for the Pure Culture}

In all analysis replicates, the results of Salmonella strains appeared as the typical ladder-like structure using $2 \% \mathrm{AGE}$, and the LFD revealed all expected positive results ( 2 red lines in the detection region). At the same time, all the results of non-Salmonella strains did not elicit amplification, and the LFD detection region only displayed the single control line (Tables 1 and 2).

The LAMP-LFD and LAMP-AGE detection limit is the same, being $3.7 \times 10^{0} \mathrm{cfu} / \mathrm{mL}$ for the pure culture, whereas the detection limit of conventional PCR is 3.7 $\times 10^{2} \mathrm{cfu} / \mathrm{mL}$ (Figure 5).

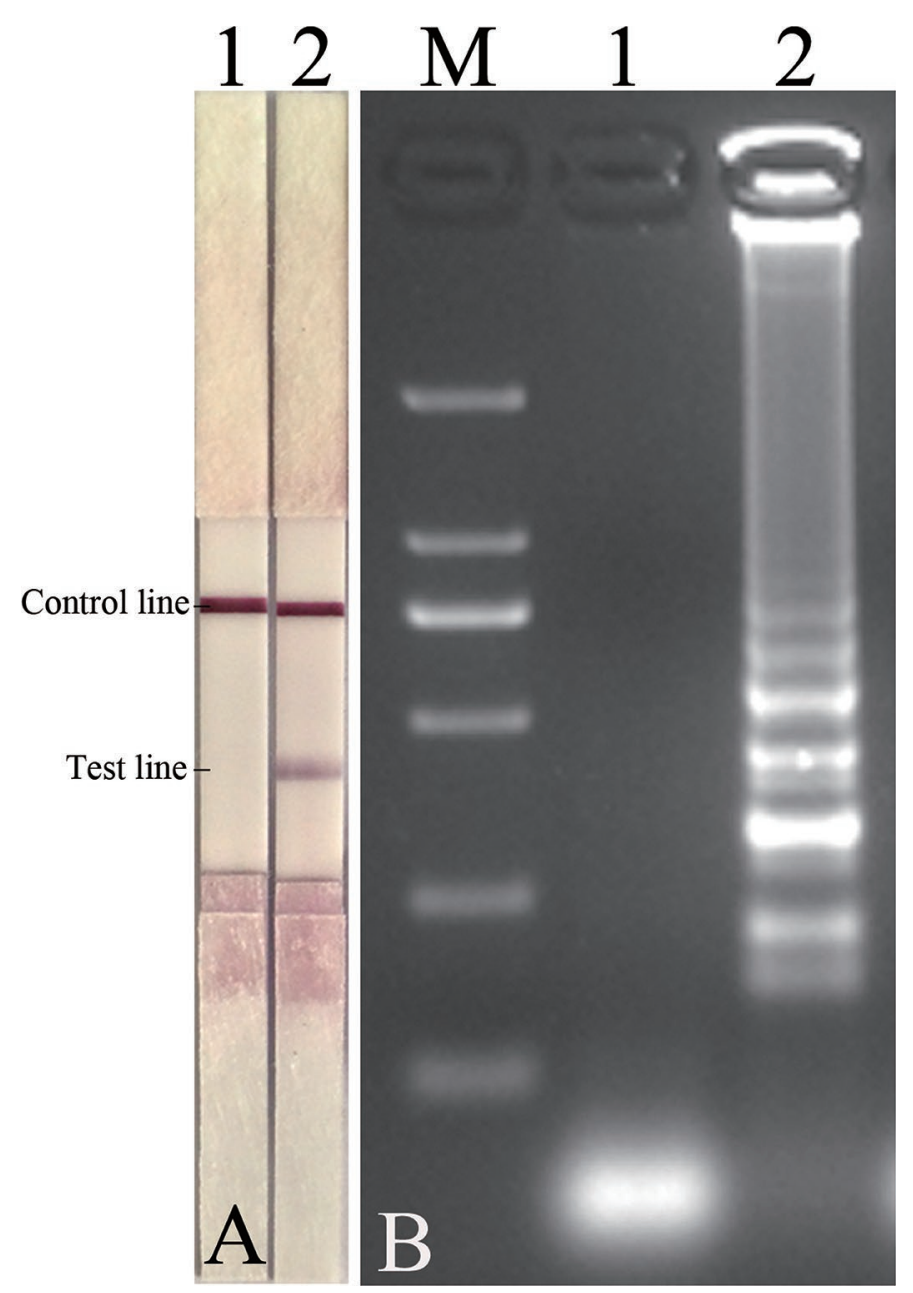

Figure 4. The methods of loop-mediated isothermal amplification-lateral flow dipstick (A) and loop-mediated isothermal amplification-agarose gel electrophoresis (B) for detection of Salmonella Typhimurium ATCC 14028. M: 2,000-bp DNA ladder; lane 1: double-distilled $\mathrm{H}_{2} \mathrm{O}$; lane 2: genomic DNA of Salmonella Typhimurium ATCC 14028. Color version available online. 

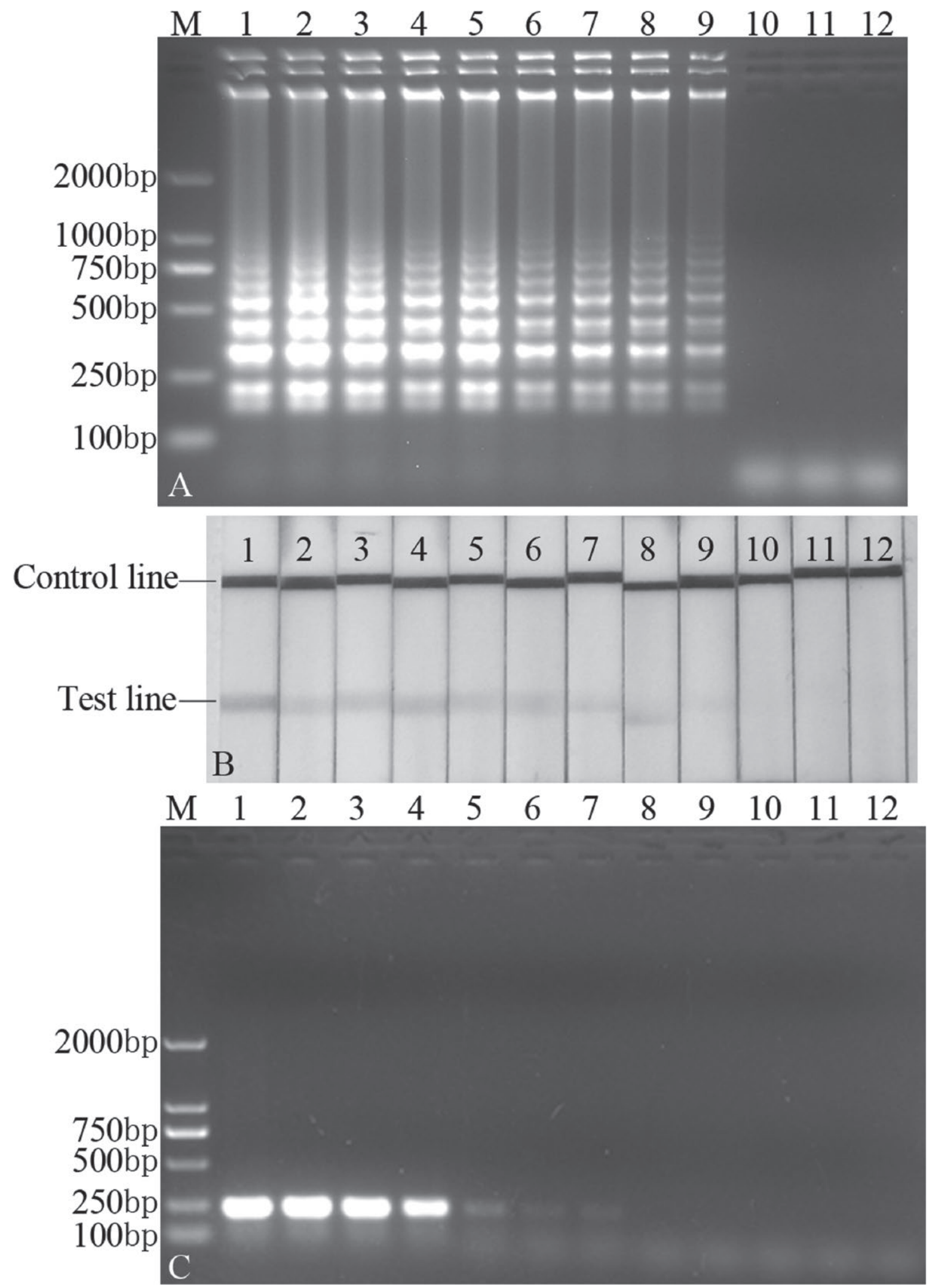

Figure 5. The sensitivity of different detection methods for the pure culture. (A) The detection method of loop-mediated isothermal amplification-agarose gel electrophoresis (LAMP-AGE). (B) The detection method of loop-mediated isothermal amplification-lateral flow dipstick (LAMP-LFD). (C) The detection method of conventional PCR. M: marker. Lanes 1 to 11: the genomic DNA of the concentrations of Salmonella Typhimurium ATCC 14028 ranging from $3.7 \times 10^{8}$ to $3.7 \times 10^{-2} \mathrm{cfu} / \mathrm{mL}$, respectively; lane 12 : negative control (double-distilled $\mathrm{H}_{2} \mathrm{O}$ ). 


\section{Sensitivity and Applicability of the LAMP-LFD in Artificially Contaminated PIF}

Three different methods have been reported to extract the template DNA in PIF: the boiling method (Li et al., 2016), the commercial Gen Elute Bacterial Genomic DNA extraction kit, and use of the chelating agent EDTA (Kumar and Mondal, 2015). We chose the best method to extract the template DNA in PIF by comparing the quality of the extraction DNA. The results verified that the commercial DNA extraction kit demonstrated the best extraction efficiency from PIF for detection of Salmonella (data not shown).

We selected PIF samples that were not already contaminated with Salmonella to artificially contaminated with varying densities of Salmonella Typhimurium ATCC 14028 without enrichment to determine the sensitivity of each detection method. The results showed that the detection methods of LAMP-AGE and LAMPLFD have the same detection limit as low as $2.2 \times 10^{0}$ $\mathrm{cfu} / \mathrm{g}$ and the PCR detection limit is $2.2 \times 10^{2} \mathrm{cfu} / \mathrm{g}$ (Figure 6).

To further determine the applicability of the LAMPLFD method, we detected 60 positive PIF samples artificially contaminated with Salmonella Typhimurium ATCC 14028 and 20 negative PIF samples that were not contaminated with Salmonella, respectively. From the results, we concluded that all 60 positive PIF samples could be detected and all 20 negative PIF samples could not be detected. In other words, the method of LAMP-LFD had a high specificity (100\%) for detection of Salmonella in PIF.

\section{PMA Treatment and Carryover Contamination}

We defined the lowest concentration without LAMP amplification bands as PMA concentration to eliminate the carryover contamination of LAMP. The final concentration $(450,126,126,90,63$, and $45 \mu M)$ of PMA can completely inhibit the re-amplifications of previous LAMP products $(100 \mathrm{ng} / \mu \mathrm{L}, 10 \mathrm{ng} / \mu \mathrm{L}, 1 \mathrm{ng} / \mu \mathrm{L}, 1$ $\mathrm{pg} / \mu \mathrm{L}, 1 \mathrm{fg} / \mu \mathrm{L}$, and $1 \mathrm{ag} / \mu \mathrm{L}$ ), respectively (Figure 7 ). In other words, $18 \mu \mathrm{L}$ of different concentrations (500, $140,100,70$, and $50 \mu M$ ) of PMA solutions can completely inhibit the re-amplifications of $2 \mu \mathrm{L}$ of previous LAMP products $(1,000 \mathrm{ng} / \mu \mathrm{L}, 100 \mathrm{ng} / \mu \mathrm{L}, 10 \mathrm{ng} / \mu \mathrm{L}$, $10 \mathrm{pg} / \mu \mathrm{L}, 10 \mathrm{fg} / \mu \mathrm{L}$, and $10 \mathrm{ag} / \mu \mathrm{L})$, respectively.

\section{PMA Photolysis}

We used the LAMP amplicons $(2-\mu \mathrm{L}$ concentrations of $10 \mathrm{ag} / \mu \mathrm{L})$ as the template for re-amplification and defined PMA to be completely inactivated when the brightness of amplification bands was measured as be- ing no lower than the positive control. In this study, we selected the shortest time for this as the photolysis time of PMA. Results showed that the concentration of $450 \mu M$ PMA does not completely undergo photolysis in less than $120 \mathrm{~min}$; the other concentrations $(126,90$, 63 , and $45 \mu M$ ) of PMA required 100, 70, 50, and 40 min to finish complete photolysis, respectively (Figure 8).

\section{PMA Applied in LAMP-LFD Detection}

The LAMP products $(2 \mu \mathrm{L}$ of $5 \mathrm{ag} / \mu \mathrm{L})$ treated by PMA did not result in re-amplification, but when treated by nuclease-free water, re-amplification did occur. The target DNA was successfully detected while the contaminants were removed simultaneously (Figure 9). These results verified that PMA can be effectively applied in eliminating LAMP carryover contaminants without affecting the LFD color observation. Meanwhile, the inactivated PMA has no detectable influence on the LAMP reaction efficiency.

\section{DISCUSSION}

Previous studies have reported that many LAMPoriented methods can detect Salmonella, but with low specificity and not combined with the LFD method (Ziemer and Steadham, 2003; Soli et al., 2013). In this study, we used the very specific and conserved Salmonella target gene siiA to establish the LAMP-LFD detection method to detect Salmonella in PIF.

In previous studies, using real-time PCR (Hyeon et al., 2010) and LAMP-AGE (Zhang et al., 2012a) to detect Salmonella required about $2 \mathrm{~h}$ and $1 \mathrm{~h} 45 \mathrm{~min}$, respectively. Meanwhile, the LAMP monitoring methods of SYBR Green I (Zhang et al., 2012a), calcein (Li et al., 2016), and real-time turbidity (Zhuang et al., 2014) achieve the results within $1 \mathrm{~h}$, but require better detection conditions or expensive instruments. In our study, the detection time of the LAMP-LFD method to detect Salmonella is less than $1 \mathrm{~h}$, and the condition requirements for monitoring the results are more general. Meanwhile, the sensitivity of LAMP-LFD for the pure cultures was $3.7 \mathrm{cfu} / \mathrm{mL}$, which is lower than previously reported such as the detection limit of $8 \times 10^{2} \mathrm{cfu} / \mathrm{mL}$ (Zhang et al., 2012a), $6.3 \times 10^{3} \mathrm{cfu} / \mathrm{mL}$ (Zhang et al., 2012b), $5 \mathrm{cfu} / \mathrm{mL}$ (Zhuang et al., 2014), and $4.1 \mathrm{cfu} /$ $\mathrm{mL}$ (Li et al., 2016). At the same time, we used the Bst 2.0 WarmStart DNA polymerase to improve the stability of the LAMP experiment and reduce the nonspecific amplification (Tanner et al., 2012). So the LAMP-LFD method we established is more rapid, convenient, and sensitive. To our best knowledge, no previous studies have used the LAMP method for detection of Salmo- 

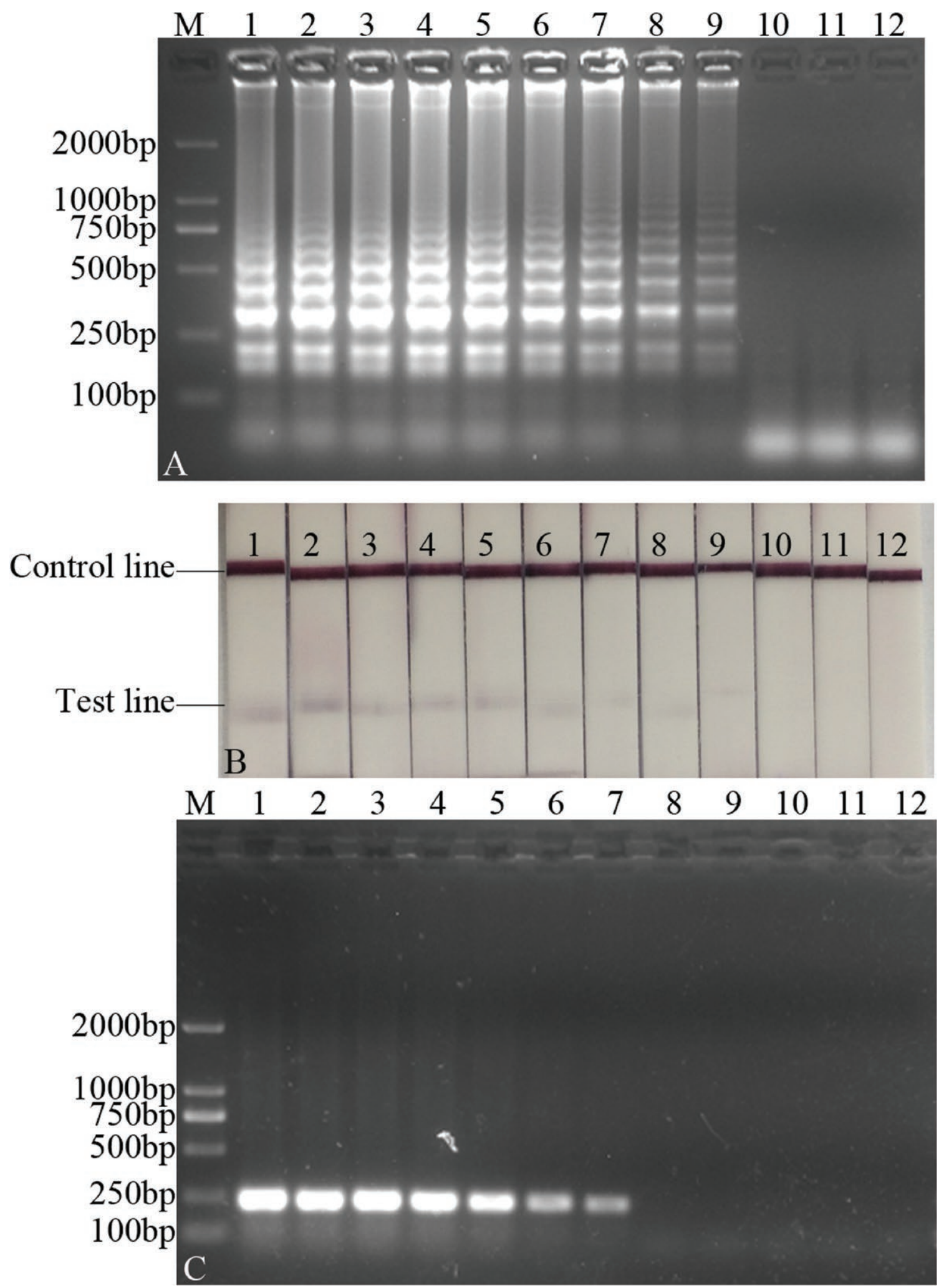

Figure 6. The sensitivity of different detection methods for artificial contamination of powdered infant formula (PIF). (A) The detection method of loop-mediated isothermal amplification-agarose gel electrophoresis (LAMP-AGE). (B) The detection method of loop-mediated isothermal amplification-lateral flow dipstick (LAMP-LFD). (C) The detection method of conventional PCR. M: marker. Lanes 1 to 11: the PIF samples were artificially contaminated with concentrations of the Salmonella Typhimurium ATCC 14028 ranging from $2.2 \times 10^{8}$ to $2.2 \times 10^{-2}$ $\mathrm{cfu} / \mathrm{g}$, respectively; lane 12: negative control (double-distilled $\mathrm{H}_{2} \mathrm{O}$ ). Color version available online. 

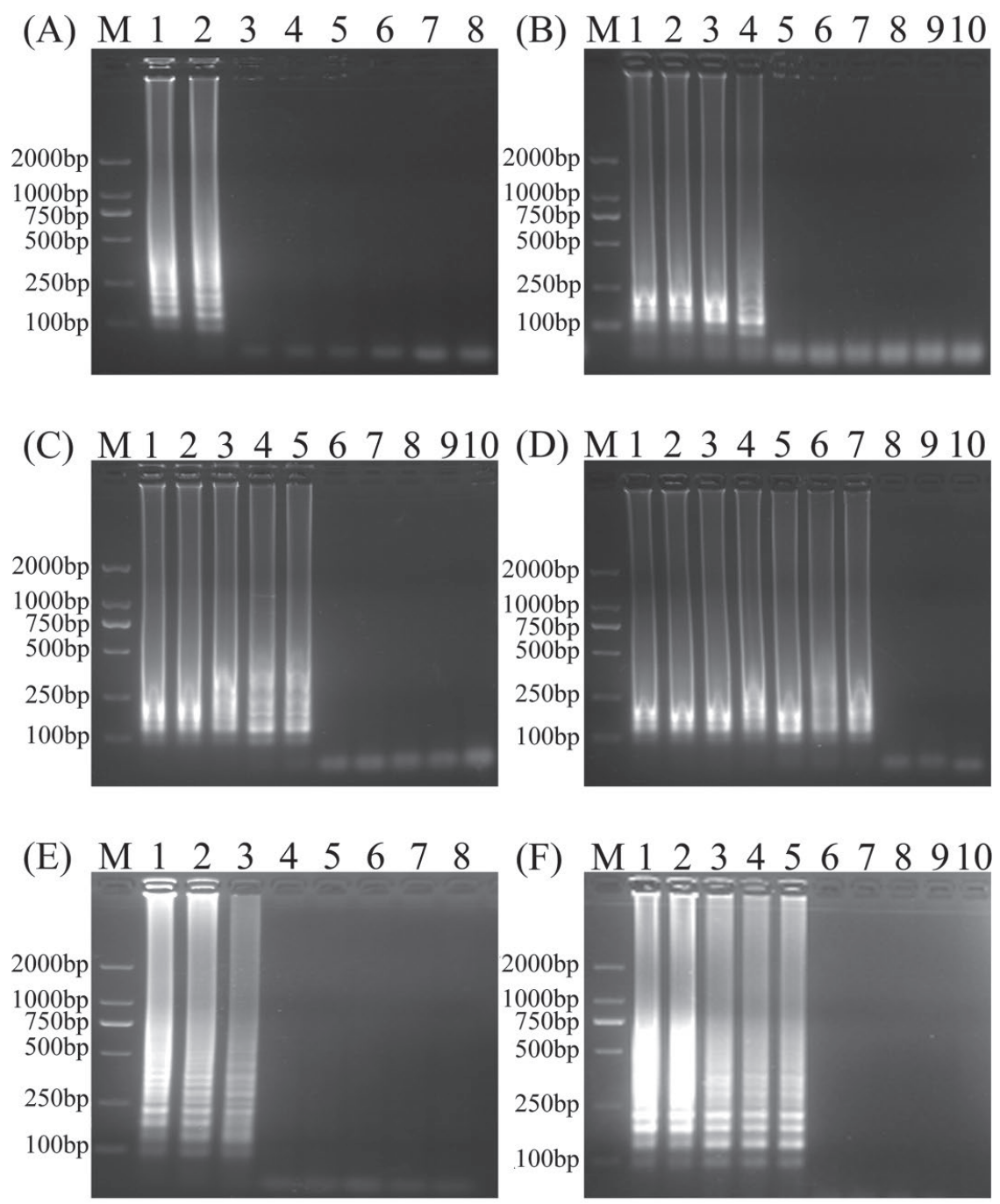

(G)



Figure 7. Concentration of propidium monoazide (PMA) eliminates carryover contamination of loop-mediated isothermal amplification (LAMP). Panels A to F show the different concentrations of LAMP products $(1 \mathrm{ag} / \mu \mathrm{L}, 1 \mathrm{fg} / \mu \mathrm{L}, 1 \mathrm{pg} / \mu \mathrm{L}, 1 \mathrm{ng} / \mu \mathrm{L}, 10 \mathrm{ng} / \mu \mathrm{L}$, and $100 \mathrm{ng} / \mu \mathrm{L}$, respectively) eliminated by different concentrations of PMA. M: marker. Panel A: lanes 1 to 7 , the final concentration of PMA is $27,36,45,54$, 63, 72, and $81 \mu M$, respectively; lane 8, negative control (NC). Panel B: lanes 1 to 9, the final concentration of PMA is 27, 36, 45, 54, 63, 81, 90, 99, and $108 \mu M$, respectively; lane 10, NC. Panel C: lanes 1 to 9, the final concentration of PMA is 45, 54, 63, 72, 81, 90, 99, 108, and 117 $\mu M$, respectively; lane 10, NC. Panel D: lanes 1 to 9, the final concentration of PMA is $63,72,81,90,99,108,117,126$, and $135 \mu M$, respectively; lane 10, NC. Panel E: lanes 1 to 7, the final concentration of PMA is 99, 108, 117, 126, 135, 144, and $153 \mu M$, respectively; lane 8, NC. Panel F: lanes 1 to 9, the final concentration of PMA is 45, 99, 180,270,360,450,540,630, and $720 \mu M$, respectively; lane 10 , NC. Panel G, the varied final concentration $(450,126,126,90,63$, and $45 \mu M)$ of PMA can completely inhibit subsequent re-amplifications of LAMP products (100 ng/ $\mu \mathrm{L}, 10 \mathrm{ng} / \mu \mathrm{L}, 1 \mathrm{ng} / \mu \mathrm{L}, 1 \mathrm{pg} / \mu \mathrm{L}, 1 \mathrm{fg} / \mu \mathrm{L}$, and $1 \mathrm{ag} / \mu \mathrm{L}$, respectively). All of the experiments were repeated in triplicate. 


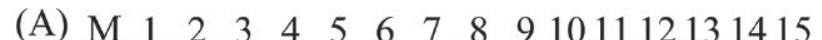



(B) $\mathrm{M} \quad 1 \quad 2 \quad 3 \quad 4 \quad 5 \quad 6 \quad 7 \quad 8 \quad 9101112131415$

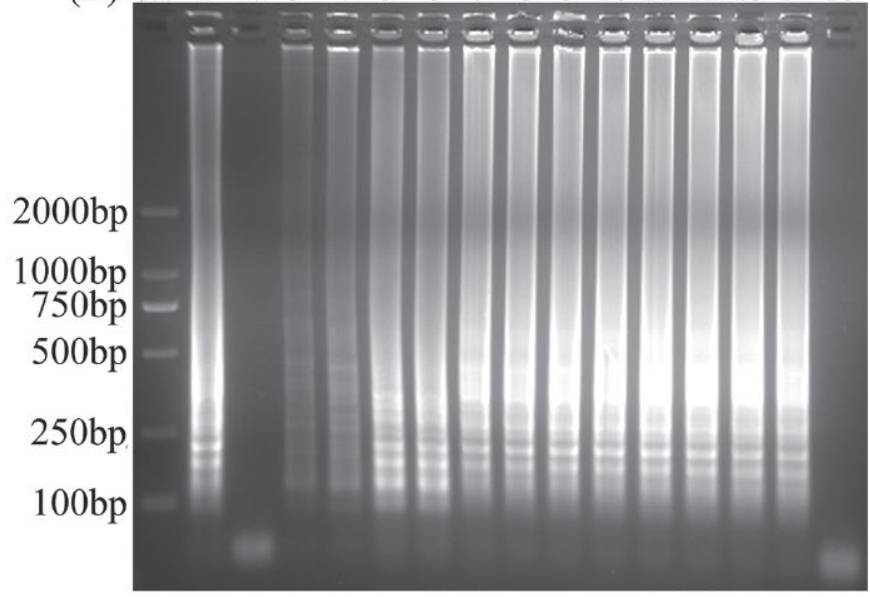

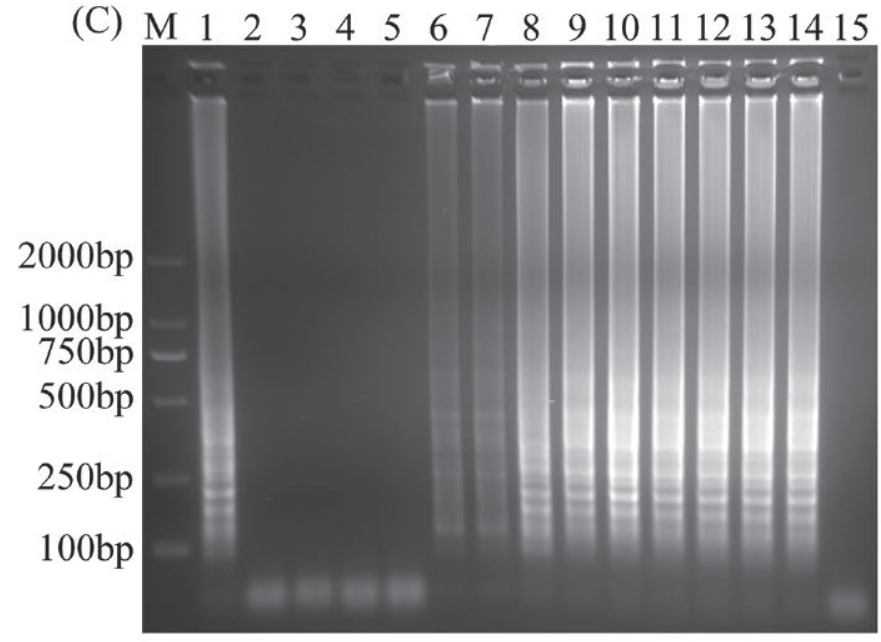

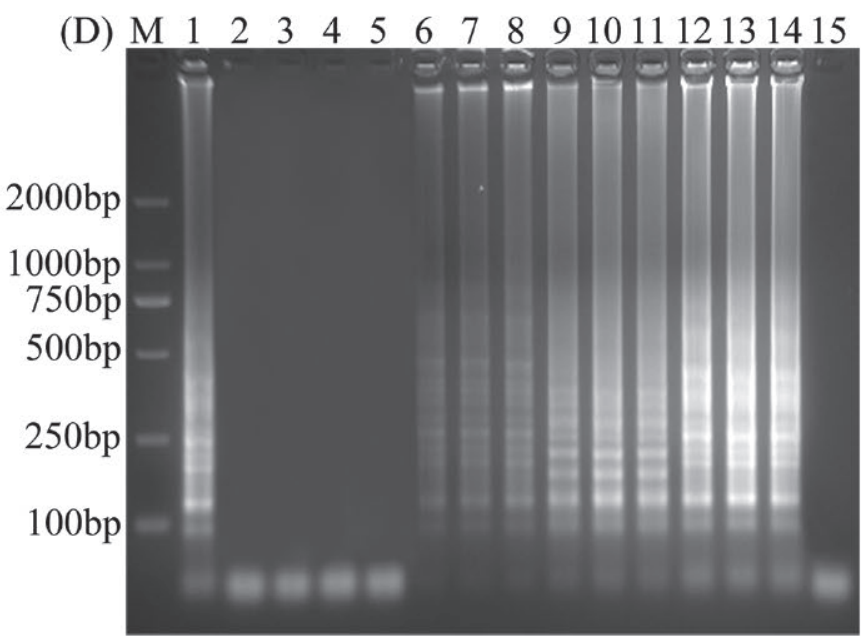

(E)

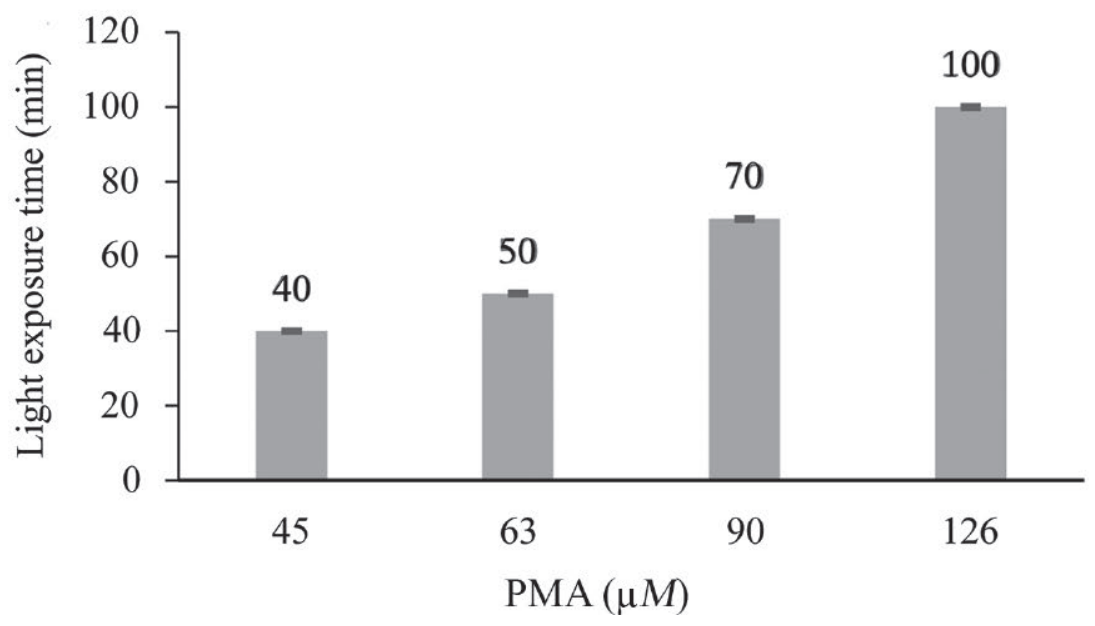

Figure 8. Time needed for complete photolysis of propidium monoazide (PMA). Panels A to D: the different final concentration of PMA (45, 63, 90 and $126 \mu M$ ) can be completely photolysis. M: marker. Lane 1: positive control; lanes 2 to 14: exposing the different concentration of PMA to a illuminance of 111,500 lx in 10-min intervals ranging from 0 to $120 \mathrm{~min}$; lane 15: negative control. Panel E: the different concentrations (45,

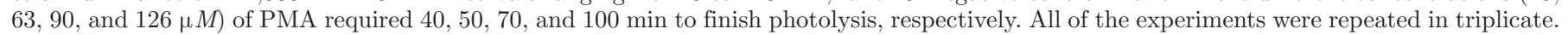




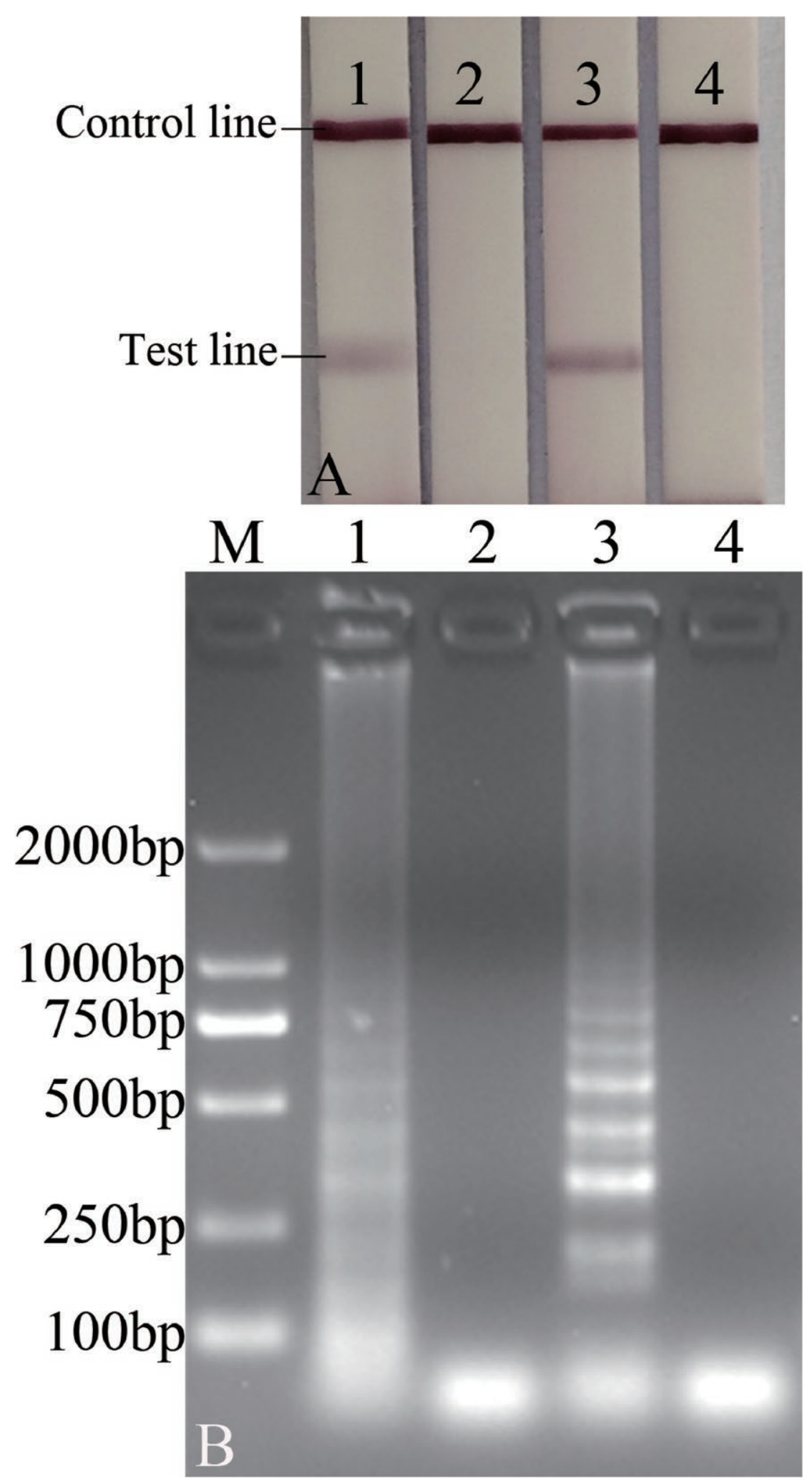

Figure 9. Propidium monoazide (PMA) can completely eliminate the carryover contamination of loop-mediated isothermal amplification (LAMP) without inhibiting LAMP amplification. $\mathrm{M}=$ marker. Lanes 1 and 2 , the mixtures (nuclease-free water and PMA were respectively mixed with LAMP products and then exposed to light) were used as a template for re-amplification; lane 3, PMA-treated mixture mixed with the target DNA was used as a template for re-amplification. Lane 4, negative control. Panels A and B used lateral flow dipstick and 2\% agarose gel electrophoresis to observe the results, respectively. All of the experiments were repeated in triplicate. Color version available online. 
nella in PIF. Only a single known study has established the method of real-time PCR to detect Salmonella in artificially contaminated PIF, with a detection limit of $10^{3} \mathrm{cfu} / \mathrm{mL}$ without enrichment (Hyeon et al., 2010). In our study, the method of LAMP-LFD detection limit of artificially contaminated PIF without enrichment was $2.2 \mathrm{cfu} / \mathrm{g}$, which is 1,000 times lower than the previous study and 100 times lower than the conventional method of PCR (Figure 5). In summary, the detection system we have established for detection of Salmonella is more rapid, accurate, sensitive, and suitable for onsite inspection of the PIF or dairy products than the previous studies.

It has been previously reported that the siiA gene is specific to Salmonella (Hassena et al., 2015). Because the siiA gene plays an extremely important role in the field of Salmonella pathogenesis, we believe it is more suitable for detecting Salmonella. In our current study, we used 21 Salmonella strains and 31 non-Salmonella strains to determine the specificity of the detection method, which we established is $100 \%$. At the same time, aiming to further determine the applicability of the LAMP-LFD method, we detected 60 positive PIF samples that were artificially contaminated with Salmonella and 20 negative PIF samples, respectively. The results verified that the LAMP-LFD method of our development have a high diagnostic specificity (100\%) for detecting Salmonella in PIF.

Some prior work has reported that the time of AuNP conjugated with antibody needed 2 h 30 min (Najian et al., 2015), 3 h 20 min (Chen et al., 2016), or 2 h (Peng et al., 2014). But in our study, the method we established to finish the conjugate process only required $45 \mathrm{~min}$, which will greatly shorten the production time of LFD and the experimental cycle. Previous research has used LFD reader to determine the optimization LFD components, but the LFD reader cannot guarantee good parallelism because of the differences among batches of the test strip. Thus, we used the detection limits of LFD under different conditions to determine the optimization LFD components. Therefore, the methods we developed provide a new platform for rapid and accurate establishment of a multi-detection LAMP-LFD system for pathogen detection in the dairy industry.

After repeated experiments, we found that the method of LAMP-LFD was easily contaminated. In other words, false-positive results will appear in the LAMPLFD detection method after several times of detection in the same place. Thus, it is of great significance to establish a method to eliminate contamination. Previous studies have reported that $1 \mathrm{ng} / \mu \mathrm{L}$ of the dead cell genomic DNA was completely inactivated by 5 $\mu M$ PMA, and $3 \mu M$ PMA can be completely inactivated by light exposure for 2 min (Nocker et al., 2006;
Schnetzinger et al., 2013). In our current study, the results confirmed that the incubation process and steps involving ice can be omitted, which will not affect PMA when used to eliminate unwanted nucleic acid (data not shown). At the same time, we demonstrated that inactivated $1 \mathrm{ng} / \mu \mathrm{L}$ of LAMP products required 126 $\mu M$ PMA (25.2 times higher than PMA treated with genomic DNA), the appropriate final concentration of PMA was positively but not linearly correlated with the concentration of LAMP products, and the masses of the re-amplification products achieved by amplifying $2 \mu \mathrm{L}$ of each concentration of products are similar (data not shown). The reasons for this might lie in each stem-loop DNA in the cauliflower-like structure of LAMP products that can be used as the new templates for re-amplification. In this study, the results verified that when the PMA does not become inactivated, the corresponding band of the LAMP products is fainter (Figure 7). As a previous study has suggested, PMA can damage the DNA polymerase due to the organic azides of their energy-rich nature (Schnetzinger et al., 2013). Therefore, we speculated that the free PMA interfere with the LAMP amplification by damaging the Bst 2.0 WarmStart DNA polymerase. Thus, it is very necessary to ensure PMA are completely inactivated and determine the relationship between the concentration of PMA and the time required for complete photolysis. The result of our study verified a positive correlation between the concentration of PMA and photolysis time. In summary, the appropriate concentration of PMA diluted by water can be applied to the working environment of any easily contaminated area and adequate light exposure conditions can complete the decontamination process. After the decontamination stage, the rest of the PMA can be deliquidated by spraying enough water to the environment treated by PMA to reduce the concentration of the free PMA and then the photolysis time of PMA can be shortened. Previous studies only measured the distance and used a blue light-emitting diode or halogen light power to evaluate the treatment conditions. Thus, our current study is the first to employ illuminance instead of the previous conditions, which can be more flexible and accurate.

Although the results of real-time LAMP can be visualized, PMA will emit a strong fluorescence when bound to nucleic acids (Venkateswaran and Smiley, 2011), and a high concentration of PMA was required for eliminating the LAMP carryover contamination. Thus, it is easy to measure a stronger signal interference in real-time LAMP. Therefore, we selected the conventional AGE method to illustrate the results. The results verified that the approach we established to eliminate carryover contamination will not affect the visual detection 
method of LAMP-LFD and is more effective (reducing the step of preparing the reaction solution and avoiding the inhibition of LAMP amplification) than other previous methods. Thus, the study will expand PMA application in the field of detection using LAMP and represents a powerful option for pathogen detection in dairy products.

\section{CONCLUSIONS}

In summary, we developed a visual LAMP-LFD method targeting the Salmonella siiA gene, which has a high specificity $(100 \%)$ and effectively shortens the detection time in a model dairy food system. At the same time, we optimized the detection method by using PMA to eliminate carryover contamination. Therefore, the methods described herein provide a rapid, accurate, and convenient detection system for detecting Salmonella in PIF, and likely several other dairy products.

\section{ACKNOWLEDGMENTS}

This work was supported by the "Academic Backbone" Project of Northeast Agricultural University (grant number 15XG26) and the Science Foundation for Distinguished Young Scholars of Heilongjiang Province (grant number JC201415, China).

\section{REFERENCES}

Alves, J., N. H. Niguma, and T. C. Oliveira. 2015. Detection of Salmonella spp. in eight complex food matrices using polymerase chain reaction assay. J. Food Saf. 35:453-457.

Bäumler, A. J., F. Heffron, and R. Reissbrodt. 1997. Rapid detection of Salmonella enterica with primers specific for iroB. J. Clin. Microbiol. 35:1224-1230.

Cahill, S. M., I. K. Wachsmuth, M. de Lourdes Costarrica, and P. K. Ben Embarek. 2008. Powdered infant formula as a source of Salmonella infection in infants. Clin. Infect. Dis. 46:268-273.

Chen, S., F. Wang, J. C. Beaulieu, R. E. Stein, and B. Ge. 2011. Rapid detection of viable Salmonellae in produce by coupling propidium monoazide with loop-mediated isothermal amplification. Appl. Environ. Microbiol. 77:4008-4016.

Chen, Y., N. Cheng, Y. Xu, K. Huang, Y. Luo, and W. Xu. 2016. Point-of-care and visual detection of $\mathrm{P}$. aeruginosa and its toxin genes by multiple LAMP and lateral flow nucleic acid biosensor. Biosens. Bioelectron. 81:317-323.

De Clercq, D., A. Ceustermans, M. Heyndrickx, J. Coosemans, and J. Ryckeboer. 2007. A rapid monitoring assay for the detection of Salmonella spp. and Salmonella Senftenberg strain W775 in composts. J. Appl. Microbiol. 103:2102-2112.

Dhama, K., K. Karthik, S. Chakraborty, R. Tiwari, S. Kapoor, A. Kumar, and P. Thomas. 2014. Loop-mediated isothermal amplification of DNA (LAMP): A new diagnostic tool lights the world of diagnosis of animal and human pathogens: A review. Pak. J. Biol. Sci. 17:151-166.

Elizaquível, P., G. Sánchez, and R. Aznar. 2012. Quantitative detection of viable foodborne $E$. coli $\mathrm{O} 157$ : H7, Listeria monocytogenes and Salmonella in fresh-cut vegetables combining propidium monoazide and real-time PCR. Food Contr. 25:704-708.
Gerlach, R. G., N. Cláudio, M. Rohde, D. Jäckel, C. Wagner, and M. Hensel. 2008. Cooperation of Salmonella pathogenicity islands 1 and 4 is required to breach epithelial barriers. Cell. Microbiol. 10:2364-2376.

Gerlach, R. G., D. Jäckel, N. Geymeier, and M. Hensel. 2007. Salmonella pathogenicity island 4-mediated adhesion is coregulated with invasion genes in Salmonella enterica. Infect. Immun. 75:46974709.

Hassena, A. B., M. Barkallah, I. Fendri, N. Grosset, I. B. Neila, M. Gautier, and R. Gdoura. 2015. Real time PCR gene profiling and detection of Salmonella using a novel target: The siiA gene. J. Microbiol. Methods 109:9-15.

He, L., and H.-s. Xu. 2011. Development of a multiplex loop-mediated isothermal amplification (mLAMP) method for the simultaneous detection of white spot syndrome virus and infectious hypodermal and hematopoietic necrosis virus in penaeid shrimp. Aquaculture 311:94-99.

Hsieh, K., P. L. Mage, A. T. Csordas, M. Eisenstein, and H. T. Soh. 2014. Simultaneous elimination of carryover contamination and detection of DNA with uracil-DNA-glycosylase-supplemented loop-mediated isothermal amplification (UDG-LAMP). Chemical Communications 50:3747-3749.

Hyeon, J.-Y., C. Park, I.-S. Choi, P. S. Holt, and K.-H. Seo. 2010. Development of multiplex real-time PCR with internal amplification control for simultaneous detection of Salmonella and Cronobacter in powdered infant formula. Int. J. Food Microbiol. 144:177-181.

Jung, J. H., S. J. Oh, Y. T. Kim, S. Y. Kim, W.-J. Kim, J. Jung, and T. S. Seo. 2015. Combination of multiplex reverse-transcription loop-mediated isothermal amplification with an immunochromatographic strip for subtyping influenza A virus. Anal. Chim. Acta 853:541-547.

Karthik, K., R. Rathore, P. Thomas, T. Arun, K. Viswas, K. Dhama, and R. Agarwal. 2014. New closed tube loop mediated isothermal amplification assay for prevention of product cross-contamination. MethodsX 1:137-143.

Khoo, C.-H., Y.-K. Cheah, L.-H. Lee, J.-H. Sim, N. A. Salleh, S. M. Sidik, S. Radu, and S. Sukardi. 2009. Virulotyping of Salmonella enterica subsp enterica isolated from indigenous vegetables and poultry meat in Malaysia using multiplex-PCR. Antonie Van Leeuwenhoek 96:441-457.

Kil, E.-J., S. Kim, Y.-J. Lee, E.-H. Kang, M. Lee, S.-H. Cho, M.K. Kim, K.-Y. Lee, N.-Y. Heo, and H.-S. Choi. 2015. Advanced loop-mediated isothermal amplification method for sensitive and specific detection of Tomato chlorosis virus using a uracil DNA glycosylase to control carry-over contamination. J. Virol. Methods 213:68-74

Kiss, T., E. Morgan, and G. Nagy. 2007. Contribution of SPI-4 genes to the virulence of Salmonella enterica. FEMS Microbiol. Lett. 275:153-159.

Kokkinos, P., P. Ziros, M. Bellou, and A. Vantarakis. 2014. Loopmediated isothermal amplification (LAMP) for the detection of Salmonella in food. Food Anal. Methods 7:512-526.

Kumar, S., and K. K. Mondal. 2015. Visual detection of Escherichia coli contamination in milk and fruit juice using loop-mediated isothermal amplification. J. Food Sci. Technol. 52:1-8. https://doi. org/10.1007/s13197-015-1779-2.

Li, J., L. Zhai, X. Bie, Z. Lu, X. Kong, Q. Yu, F. Lv, C. Zhang, and H. Zhao. 2016. A novel visual loop-mediated isothermal amplification assay targeting gene62181533 for the detection of Salmonella spp. in foods. Food Contr. 60:230-236.

Luk, J. M., U. Kongmuang, P. Reeves, and A. Lindberg. 1993. Selective amplification of abequose and paratose synthase genes ( $\mathrm{rbb}$ ) by polymerase chain reaction for identification of Salmonella major serogroups (A, B, C2, and D). J. Clin. Microbiol. 31:2118-2123.

Maciel, B. M., J. Dias, C. Romano, N. Sriranganathan, M. Brendel, and R. Rezende. 2011. Detection of Salmonella Enteritidis in asymptomatic carrier animals: Comparison of quantitative realtime PCR and bacteriological culture methods. Genet. Mol. Res. 10:2578-2588. 
Mori, Y., and T. Notomi. 2009. Loop-mediated isothermal amplification (LAMP): A rapid, accurate, and cost-effective diagnostic method for infectious diseases. J. Infect. Chemother. 15:62-69.

Moussa, I., M. Gassem, A. Al-Doss, W. Sadik, and A. A. Mawgood. 2010. Using molecular techniques for rapid detection of Salmonella serovars in frozen chicken and chicken products collected from Riyadh, Saudi Arabia. Afr. J. Biotechnol. 9:612-619.

Najian, A. N., E. E. N. Syafirah, N. Ismail, M. Mohamed, and C. Y. Yean. 2015. Development of multiplex loop mediated isothermal amplification (m-LAMP) label-based gold nanoparticles lateral flow dipstick biosensor for detection of pathogenic Leptospira. Analytica Chimica Acta 903:142-148.

Nocker, A., C.-Y. Cheung, and A. K. Camper. 2006. Comparison of propidium monoazide with ethidium monoazide for differentiation of live vs. dead bacteria by selective removal of DNA from dead cells. J. Microbiol. Methods 67:310-320.

Notomi, T., H. Okayama, H. Masubuchi, T. Yonekawa, K. Watanabe, N. Amino, and T. Hase. 2000. Loop-mediated isothermal amplification of DNA. Nucleic Acids Res. 28:E63.

Ou, X., Q. Li, H. Xia, Y. Pang, S. Wang, B. Zhao, Y. Song, Y. Zhou, Y. Zheng, and Z. Zhang. 2014. Diagnostic accuracy of the PURELAMP test for pulmonary tuberculosis at the county-level laboratory in China. PLoS One 9:e94544.

Peng, T., W.-C. Yang, W.-H. Lai, Y.-H. Xiong, H. Wei, and J. Zhang. 2014. Improvement of the stability of immunochromatographic assay for the quantitative detection of clenbuterol in swine urine. Anal. Methods 6:7394-7398.

Ravan, H., and R. Yazdanparast. 2012. Development and evaluation of a loop-mediated isothermal amplification method in conjunction with an enzyme-linked immunosorbent assay for specific detection of Salmonella serogroup D. Anal. Chim. Acta 733:64-70.

Rigano, L. A., F. Malamud, I. G. Orce, M. P. Filippone, M. R. Marano, A. M. do Amaral, A. P. Castagnaro, and A. A. Vojnov. 2014. Rapid and sensitive detection of Candidatus Liberibacter asiaticus by loop mediated isothermal amplification combined with a lateral flow dipstick. BMC Microbiol. 14:86.

Safavieh, M., M. U. Ahmed, M. Tolba, and M. Zourob. 2012. Microfluidic electrochemical assay for rapid detection and quantification of Escherichia coli. Biosens. Bioelectron. 31:523-528.

Salam, F., Y. Uludag, and I. E. Tothill. 2013. Real-time and sensitive detection of Salmonella Typhimurium using an automated quartz crystal microbalance (QCM) instrument with nanoparticles amplification. Talanta 115:761-767.

Salzman, N. H., D. Ghosh, K. M. Huttner, Y. Paterson, and C. L. Bevins. 2003. Protection against enteric salmonellosis in transgenic mice expressing a human intestinal defensin. Nature 422:522-526.

Schnetzinger, F., Y. Pan, and A. Nocker. 2013. Use of propidium monoazide and increased amplicon length reduce false-positive signals in quantitative PCR for bioburden analysis. Appl. Microbiol. Biotechnol. 97:2153-2162.

Smith, K. P., J. George, K. M. Cadle, S. Kumar, S. J. Aragon, R. L. Hernandez, S. E. Jones, J. L. Floyd, and M. F. Varela. 2010. Elucidation of antimicrobial susceptibility profiles and genotyping of Salmonella enterica isolates from clinical cases of salmonellosis in New Mexico in 2008. World J. Microbiol. Biotechnol. $26: 1025-1031$

Soli, K. W., M. Kas, T. Maure, M. Umezaki, A. Morita, P. M. Siba, A. R. Greenhill, and P. F. Horwood. 2013. Evaluation of colorimetric detection methods for Shigella, Salmonella, and Vibrio cholerae by loop-mediated isothermal amplification. Diagn. Microbiol. Infect. Dis. 77:321-323.

Tanner, N. A., Y. Zhang, and T. C. Evans Jr.. 2012. Simultaneous multiple target detection in real-time loop-mediated isothermal amplification. Biotechniques 53:81-89.

Turki, Y., H. Ouzari, I. Mehri, R. Ben Aissa, and A. Hassen. 2012. Biofilm formation, virulence gene and multi-drug resistance in Salmonella Kentucky isolated in Tunisia. Food Res. Int. 45:940-946.

Venkateswaran, K. J., and R. D. Smiley. 2011. Methods for detecting and quantifying viable bacterial endo-spores. Google Patents.

Wang, F., L. Jiang, and B. Ge. 2012. Loop-mediated isothermal amplification assays for detecting Shiga toxin-producing Escherichia coli in ground beef and human stools. J. Clin. Microbiol. 50:91-97.

Wang, K.-C., Y.-H. Hsu, Y.-N. Huang, T.-H. Chen, J.-H. Lin, S.-L. Hsuan, M.-S. Chien, W.-C. Lee, and K.-S. Yeh. 2013. A low-pH medium in vitro or the environment within a macrophage decreases the transcriptional levels of fimA, fimZ and lrp in Salmonella enterica serovar Typhimurium. J. Biosci. 38:499-507.

Wille, T., C. Wagner, W. Mittelstädt, K. Blank, E. Sommer, G. Malengo, D. Döhler, A. Lange, V. Sourjik, and M. Hensel. 2014. SiiA and $\mathrm{SiiB}$ are novel type I secretion system subunits controlling SPI4-mediated adhesion of Salmonella enterica. Cell. Microbiol. $16: 161-178$.

Wu, R., X. Liu, B. Guo, F. Chen, and X. Wang. 2014. Development of double loop-mediated isothermal amplification to detect Listeria monocytogenes in food. Curr. Microbiol. 69:839-845.

Zhang, L., Z.-m. Pan, S.-z. Geng, X. Chen, Z.-Y. Liu, F. Zhao, and X.a. Jiao. 2012a. A loop-mediated isothermal amplification method targets the HisJ gene for the detection of foodborne Salmonella. Eur. Food Res. Technol. 234:1055-1062.

Zhang, S., R. A. Kingsley, R. L. Santos, H. Andrews-Polymenis, M. Raffatellu, J. Figueiredo, J. Nunes, R. M. Tsolis, L. G. Adams, and A. J. Bäumler. 2003. Molecular pathogenesis of Salmonella enterica serotype Typhimurium-induced diarrhea. Infect. Immun. $71: 1-12$.

Zhang, Y., X. Shan, L. Shi, X. Lu, S. Tang, Y. Wang, Y. Li, M. Alam, and H. Yan. 2012b. Development of a fimY-based loop-mediated isothermal amplification assay for detection of Salmonella in food. Food Res. Int. 45:1011-1015.

Zhao, S., S. Qaiyumi, S. Friedman, R. Singh, S. Foley, D. White, P. McDermott, T. Donkar, C. Bolin, and S. Munro. 2003. Characterization of Salmonella enterica serotype Newport isolated from humans and food animals. J. Clin. Microbiol. 41:5366-5371.

Zhao, X.. L. Wang, J. Chu, Y. Li, Y. Li, Z. Xu, L. Li, M. E. Shirtliff, X. He, and Y. Liu. 2010. Development and application of a rapid and simple loop-mediated isothermal amplification method for foodborne Salmonella detection. Food Sci. Biotechnol. 19:1655-1659.

Zhuang, L., J. Gong, Q. Li, C. Zhu, Y. Yu, X. Dou, X. Liu, B. Xu, and C. Wang. 2014. Detection of Salmonella spp. by a loop-mediated isothermal amplification (LAMP) method targeting bcfD gene. Lett. Appl. Microbiol. 59:658-664.

Ziemer, C. J., and S. Steadham. 2003. Evaluation of the specificity of Salmonella PCR primers using various intestinal bacterial species. Lett. Appl. Microbiol. 37:463-469. 